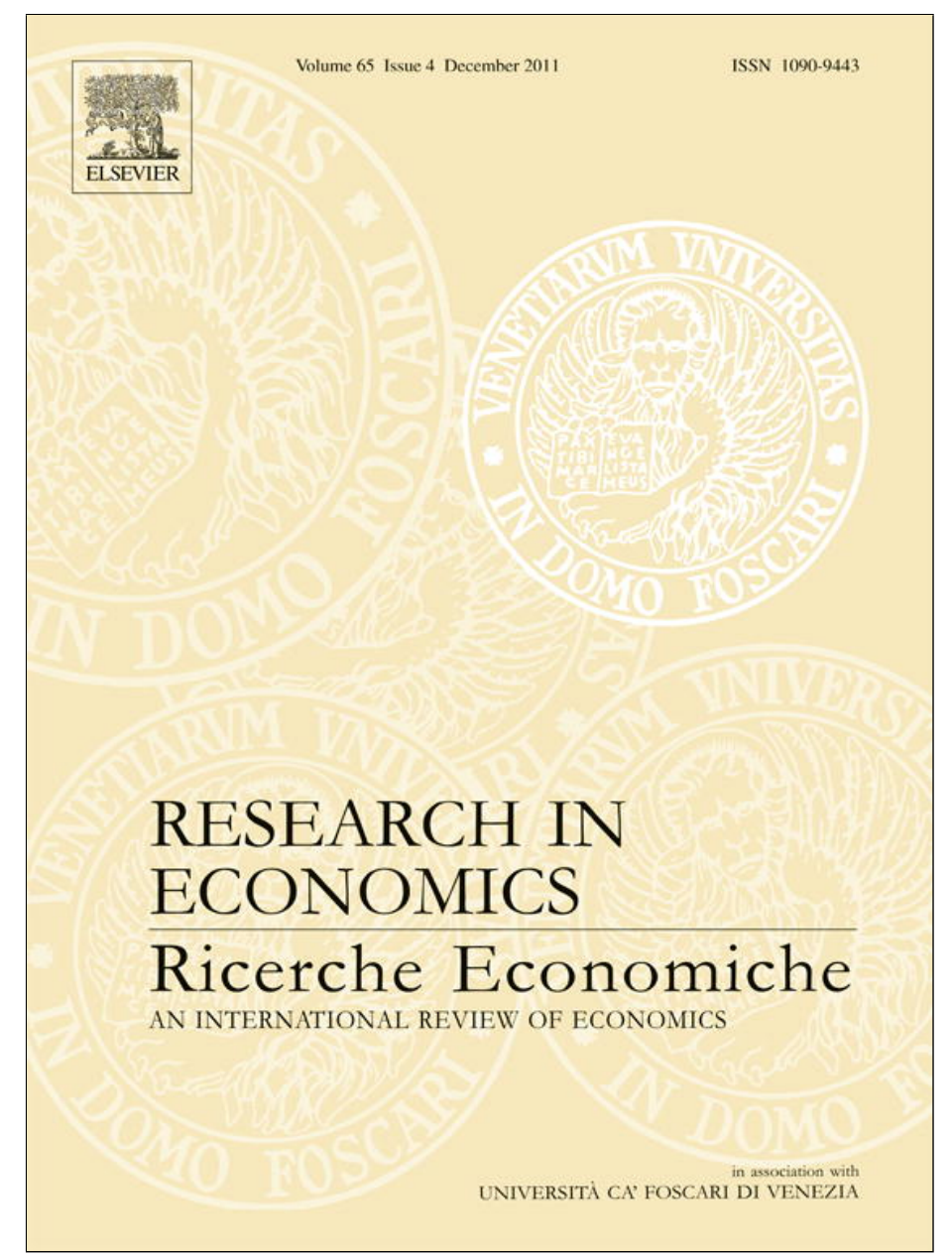

This article appeared in a journal published by Elsevier. The attached copy is furnished to the author for internal non-commercial research and education use, including for instruction at the authors institution and sharing with colleagues.

Other uses, including reproduction and distribution, or selling or licensing copies, or posting to personal, institutional or third party websites are prohibited.

In most cases authors are permitted to post their version of the article (e.g. in Word or Tex form) to their personal website or institutional repository. Authors requiring further information regarding Elsevier's archiving and manuscript policies are encouraged to visit:

http://www.elsevier.com/copyright 


\title{
Culture and human capital in a two-sector endogenous growth model ${ }^{\text {t }}$
}

\author{
Alberto Bucci ${ }^{\mathrm{a}, *}$, Giovanna Segre ${ }^{\mathrm{b}, 1}$ \\ a Department of Economics, Business and Statistics (DEAS), University of Milan, Via Conservatorio 7, I-20122 Milan, Italy \\ b School of Economics, Department of Economics and Public Finance “G. Prato”, University of Turin, Corso Unione Sovietica 218-bis, I-10134 Turin, Italy
}

\section{A R T I C L E I N F O}

\section{Article history:}

Received 15 January 2010

Accepted 29 November 2010

\section{Keywords:}

Endogenous growth

Culture

Human capital

Complementarities

Externalities

\begin{abstract}
A B S T R A C T
Recent literature in the field of cultural economics highlights a possible inversion in the usual causality relation (from economic growth to culture) and points out that culture may represent an important driver of economic growth. By viewing culture in line with Throsby's (2001) definition of cultural capital (i.e., an asset of tangible and intangible cultural expressions), in this article we analyze one possible channel through which culture may positively affect economic growth, namely the existence of a relationship of complementarity between cultural and human capital investments. Using a two-sector endogenous growth model, we find that in the long run a higher growth rate of real per-capita income can be attained the more cultural and human capital investments are complementary for each other in the process leading to agents' skill acquisition. We also analyze the conditions under which an increase of the cultural capital share in total GDP can be conducive to a rise of real per-capita income.
\end{abstract}

(c) 2010 University of Venice. Published by Elsevier Ltd. All rights reserved.

\section{Introduction}

Among the possible sources of economic growth, human capital investment plays a central role within the new growth theory. However, despite the strong theoretical support, empirical evidence that increases in educational attainments lead unambiguously to faster per-capita income growth is unexpectedly not clear-cut. Indeed, empirical results on the relationship between human capital and living standards still remain largely controversial, depending on: (i) The methodological approach used, whether cross-country growth accounting (Benhabib and Spiegel, 1994; Krueger and Lindahl, 2001; Pritchett, 2001; Caselli, 2005, among others) or cross-country growth regressions (Barro, 1999; Easterly and Levine, 1997; Islam, 1995); (ii) The measure of human capital employed ${ }^{2}$ and, finally; (iii) The type of data utilized. In this regard, studies using cross-section data, unlike those based on panel data, conclude that human capital accumulation has a positive effect on the rate of growth of real per-capita income. Islam (1995, p. 1153) summarizes this finding by observing that: “...Whenever researchers have attempted to incorporate the temporal dimension of human capital variables into growth regressions, outcomes of either statistical insignificance or negative sign have surfaced". ${ }^{3}$ Today, there exist many

\footnotetext{
We thank Professor I. Musu for insightful comments and remarks on a first draft of this paper. Responsibility for any remaining errors and/or omissions lies exclusively with the authors.

* Corresponding author. Tel.: +3902 50321 463; fax: +390250321505.

E-mail addresses: alberto.bucci@unimi.it (A. Bucci), segre@econ.unito.it (G. Segre).

1 Tel.: +39011 6706089; fax: +390116706062.

2 Wößmann (2003) provides a detailed survey of all the main measures of human capital used to date by empirical studies on growth (in particular adult literacy rates, school enrollment ratios and average years of schooling of the working-age population), and analyzes the pros and cons of each of them.

3 See also Topel (1999) and Mathur (1999) for reviews.
} 
different attempts at explaining this puzzle, mainly based on a more careful analysis of both data and estimation-techniques problems. $^{4}$

Within this framework we suggest that, in a world where complementarities (especially those involving human capital) are important, another variable that may be of particular interest in explaining economic growth is culture. Although extremely important, the analysis of the long-run effects of culture on economic growth still remains a research topic almost completely neglected by endogenous growth theory.

Culture is often considered just as one of the possible outcomes of personal wealth and/or political power. However, recent developments in the field of cultural economics highlight a likely inversion in the usual causality (from economic growth to culture) and point out that the investment in culture may represent another important engine of long-run economic growth.

Cultural production generates, directly and indirectly, substantial economic effects. The traditional view according to which the cultural value produced has to be simply considered a merit good requiring some public transfers has been abandoned. ${ }^{5}$ We are now witnessing an increase in the economic importance of cultural industry - where the large and industrial-scale production, typical of film, music, broadcasting, publishing and print sectors, takes place - while assisting at the same time to a widening of the borders of cultural industry as a productive sector per se. ${ }^{6}$ This is certainly a direct source of overall economic growth.

Besides its direct effects, however, cultural production can generate substantial economic effects also indirectly. ${ }^{7}$ Cultural industries are a driver of economic growth because numerous externalities originate from the creative sectors and spill over onto other productive sectors. More generally, the system of cultural values and the culture-rich environment created by the creative industries stimulate the production of new ideas and new technologies. Culture has also an important function of animation and enhancement of the quality of life, which is an increasingly important element in determining a particular area's competitiveness and attractiveness for residents, tourists and firms. Culture may also contribute to a more balanced and sustainable economic development since it provides opportunities for personal enrichment and social interaction among weaker groups, and gives to "excluded" individuals a chance to start their own businesses or to catch up socially. Furthermore, because cultural industries are typically labor-intensive, culture sustains labor markets. Consistently with this idea, different programs of economic valorization have been added in many countries in the 1990s to the traditional activities of preservation and conservation of historical and artistic heritage with the specific objective of sustaining and accelerating long-run economic growth.

The definition of culture we use in the present paper is strictly related to the one given by Throsby (2001) who introduces in the literature the concept of cultural capital viewed as a stock of tangible and intangible cultural expressions. The stock of tangible cultural capital exists in buildings, structures, sites and locations endowed with cultural significance (heritage) and in artworks and artifacts existing as private goods, such as paintings, sculptures, and other objects. Intangible cultural capital comprises the set of ideas, practices, beliefs, traditions and values which serve to identify a certain group of people, together with the stock of artworks existing in the public domain as public goods, such as certain instances of literature and music.

In a recent work Sacco and Segre (2009) highlight a general lack of investigation of the causal relationships involving the factors through which culture may affect economic growth, and suggest an endogenous growth mechanism sustained by cultural investment. Among the possible channels identified by the authors, in this paper we focus on human capital accumulation and emphasize the important role played in economic growth by the existence of a complementarityrelationship between cultural and human capital investments.

More specifically, in the present paper we investigate the role of cultural capital in fostering economic growth by modeling human capital investment as an economic activity being not only relatively intensive in human capital as an input, ${ }^{8}$ but also driven by the presence of complementarities with cultural capital accumulation. Our theoretical model serves, thus, two main purposes. The first is to show that, in a setting where two reproducible factor inputs (human and cultural capital) do exist, in the long run the endogenous growth rate of real per-capita income is higher the more human and cultural capital investments are complementary for each other. Therefore, our claim is that the main channel through which (the investment in) culture can affect economic growth is the one passing through the complementarity between the two forms of capital accumulation. The second objective of the model is to analyze quantitatively the conditions under which an increase of the cultural capital share in total GDP can lead to a rise of real per-capita income, as empirical evidence seems to suggest most.

The paper is organized as follows. The results of a first look at some available data and simple empirical evidence about the relationship between per-capita GDP and possible measures of cultural capital are presented in Section 2. In Section 3 we further extend the conceptual framework that links economic growth and culture to the analysis of the role of creativity.

\footnotetext{
4 Notable examples include Temple (1999, 2001), Benhabib and Spiegel (2005), Bassanini and Scarpetta (2002).

5 See Cunningham et al. (2008) for a description of the different approaches followed by the cultural economic literature.

6 In the literature, no clear agreement exists as to which industries should or should not be included in the cultural sector of the economy, and the definition of cultural or creative industries is still a matter of debate (Throsby, 2008).

7 See, among others, Scott, 2000; Santagata, 2002; Florida, 2002, 2005.

8 This is the traditional way of describing the process of education, or human capital accumulation, in the new growth theory.
} 

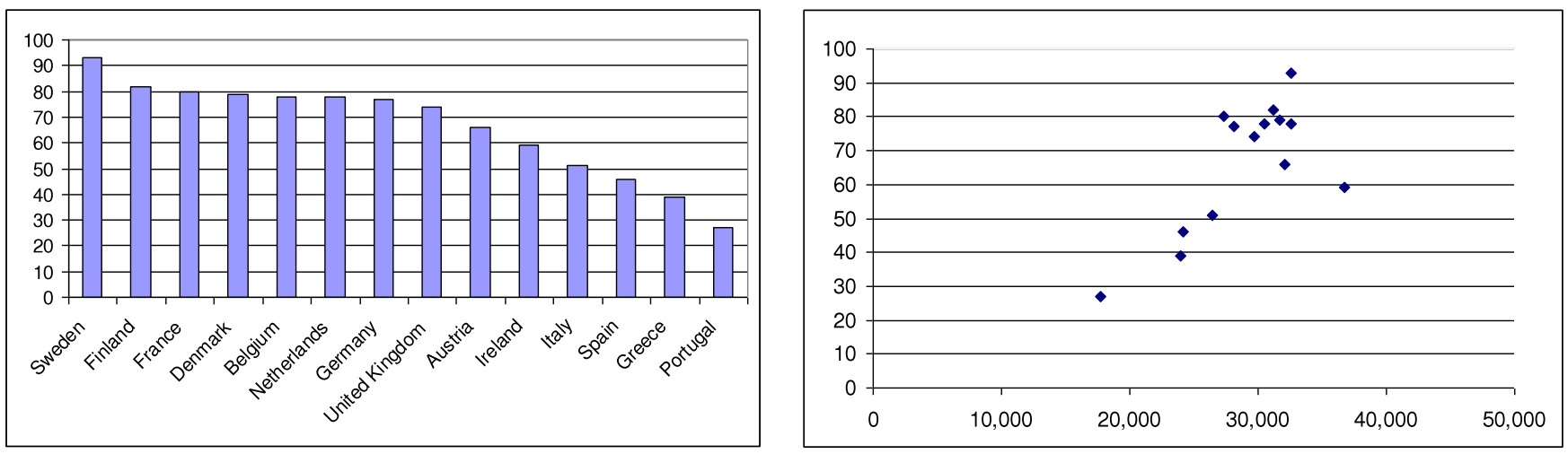

SOURCE: Eurostat (2007) and OECD (www.oecd.org) for GDP per capita.

Fig. 1. Percentage of people participating in artistic activities and the relation with GDP per capita (US \$).

This is done in order to support our claim that, in a complementarity relation with human capital accumulation, cultural capital investment may be a key element in sustaining balanced, long-run economic growth. In this section we also present the main features of a two-sector endogenous growth model and discuss its most relevant results. Section 4 concludes.

\section{Culture and macroeconomic performance}

If a role for cultural capital in economic growth does exist, a crucial point is how to measure it. Unfortunately, cultural statistics are not available yet on a comparative basis and with time-series information. ${ }^{9}$ Nevertheless, one significant indicator that can shed some light on the relation between economic growth and cultural capital is cultural participation. Data on cultural participation are taken from the Eurobarometer survey on cultural values within Europe (European Commission, 2007), which measures the proportion of people participating in some artistic activity. ${ }^{10}$ In general, the results highlight the fact that the vast majority of Europeans see culture as playing an important role in their own lives. Over three-quarters agree that culture is important to them personally, and the majority says that they are interested in arts and culture. Participation in artistic and creative activity is generally higher amongst the youngest age groups and those educated for the longest.

Fig. 1 presents the findings of this survey in a decreasing order of participation in some artistic activity (left-hand panel of the figure) for the EU-15, excluding Luxembourg. Fig. 1 also presents a first attempt at investigating empirically the relation between cultural capital and economic development, plotting (on the right-hand panel) the relation between the percentage of people participating in artistic activities ( $y$-axis) and the level of GDP per capita in 2007 (in US dollars, $x$-axis). The figure shows a striking positive correlation: the richer the country, the higher the percentage of people involved in cultural and artistic activities. This result is usually interpreted as the effect of a supposed luxury-good nature of culture. However, in our model we aim at suggesting that a positive impact of the investment in culture (or cultural capital, see Throsby, 2001) on economic growth may also occur through the existence of complementarities with skill acquisition.

A thorough empirical investigation of the relation between culture and economic growth certainly needs a time-series dimension, but the only available database on cultural activities is the one published by OECD (2006) in the Factbook on Economic, Environmental and Social Statistics where just private and public expenditures on recreation and culture are presented. In particular, two variables are available: household expenditure (HHE) and government expenditure (GE). The total expenditure on recreation and culture is also available as the sum of HHE and GE. On the one hand, we notice that these three variables group together different types of expenditures, unfortunately not all strictly related to Throsby's definition of cultural capital (the focus of this paper). ${ }^{11}$ On the other hand, the dataset allows extending the analysis to a wider set of countries and, as already mentioned gives the possibility of time-series investigations. Fig. 2 shows the average level of

\footnotetext{
9 In response to the evident lack of (and the increasing demand for) this kind of data, in 1997 the Leadership Group on Cultural Statistics was set up, and in 2000 it was converted into the Eurostat Working Party with mandate to collect harmonized data on cultural employment, cultural expenditures and participation in cultural activities. In 2007 a first edition of Cultural Statistics in Europe was released by Eurostat (2007), but without any attempt at delivering time-series information.

10 In the Eurobarometer surveys the data presented are not statistical tools but opinion-polls based on subjective responses. In this survey the respondents are asked about their active involvement (on an amateur-basis) in a set of different artistic activities, whether individually or as a part of an organized group.

11 Household expenditure on recreation and culture includes purchases of audio-visual, photographic and computer equipment, CDs and DVDs, musical instruments, camper vans, caravans, sports equipment, toys, domestic pets and related products, gardening tools and plants, newspapers, tickets to sporting matches, cinemas and theatres, and spending on gambling (including lottery tickets) less any winnings. It excludes expenditures on restaurants, hotels, and travel and holiday homes but includes package holidays. Government expenditures on recreation and culture include administration of sporting, recreational and cultural affairs as well as the maintenance of zoos, botanical gardens, public beaches and parks; support for broadcasting services and, where present, support for religious, fraternal, civic, youth and other social organizations (including the operation and repair of facilities and payment to clergy and other officers). Also included are grants to artists and arts companies. Capital outlays such as the construction of sports stadiums, public swimming pools, national theatres, opera houses and museums are included.
} 


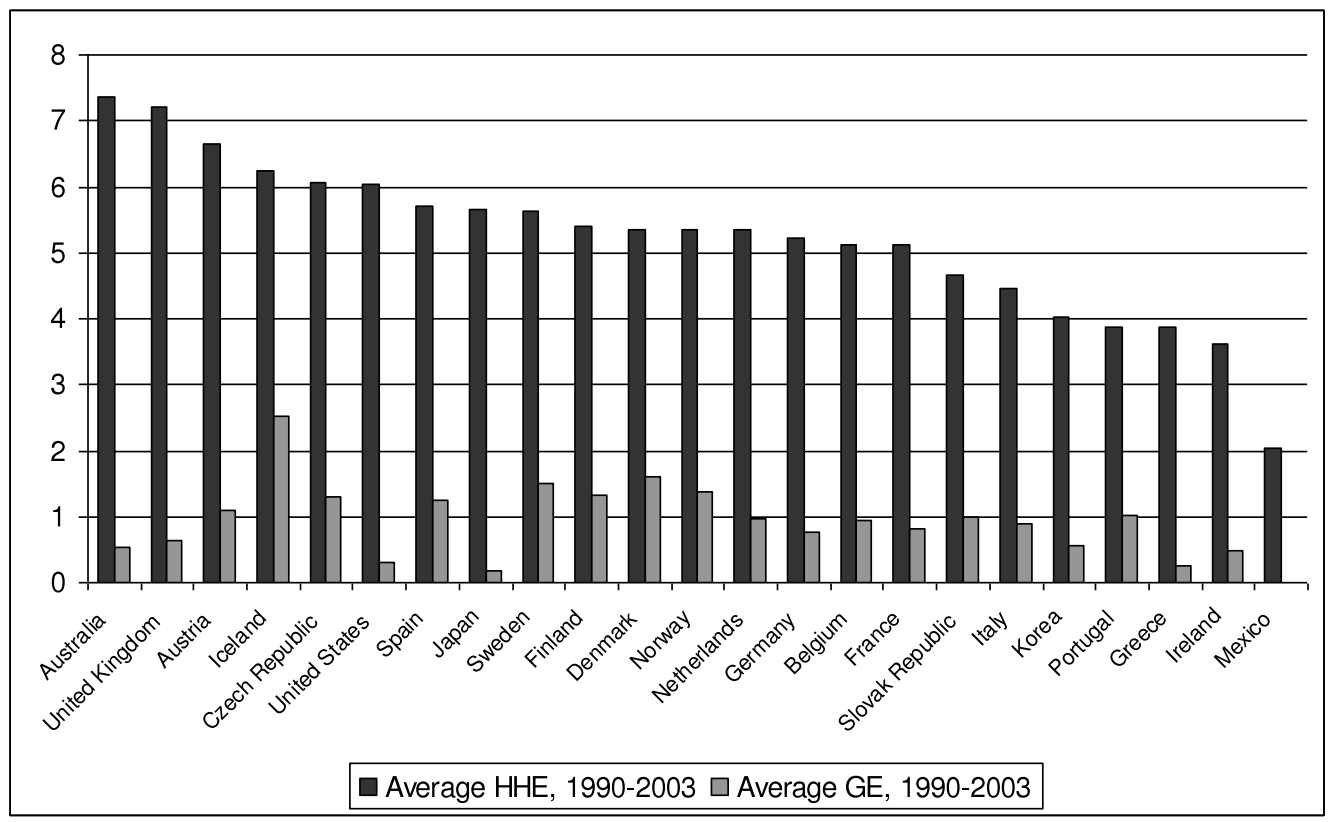

NotE: Average of the period 1990-2003, as a percentage of GDP.

HHE: Household expenditure. GE: Government expenditure. For Mexico GE is not available.

SOURCE: Authors' own calculations on OECD (2006) data.

Fig. 2. Household and government expenditures on recreation and culture (GDP\%).

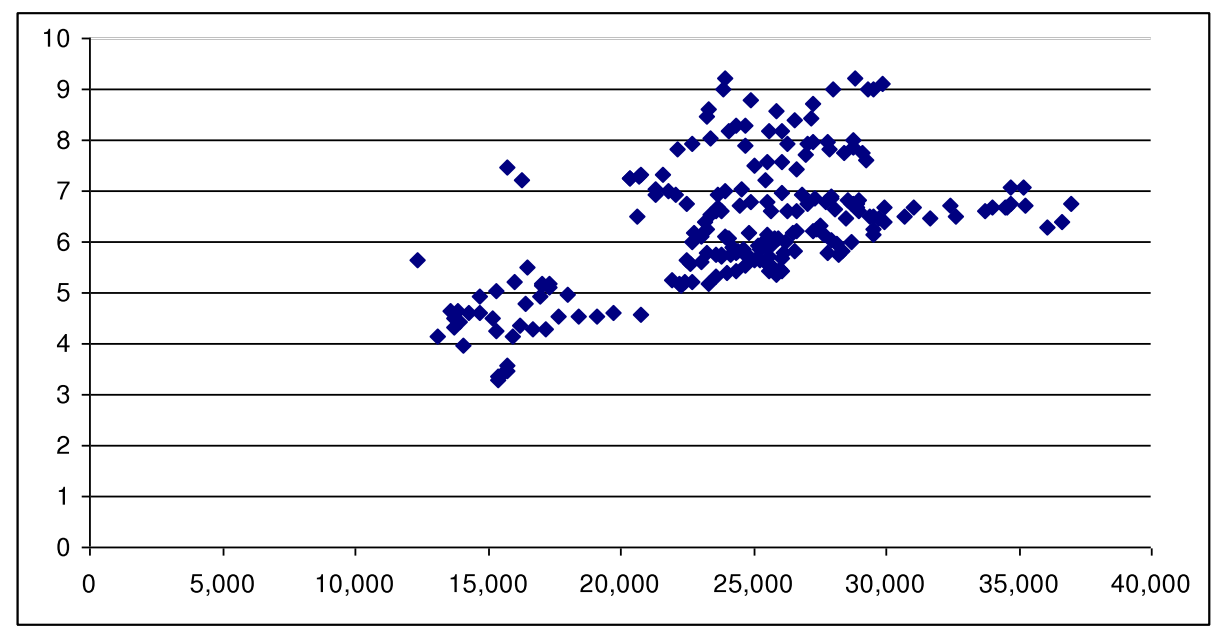

NoTE: 21 countries are plotted for the period 1990-2003.

SOURCE: Author's own calculations on OECD (2006) data and OECD (www.oecd.org) for GDP per capita.

Fig. 3. Total expenditures on recreation and culture (GDP\%) and GDP per capita (US \$).

private and public expenditures on recreation and culture, between 1990 and 2003, as a percentage of GDP for a sample of $23 \mathrm{OECD}$ countries. The figure displays (in a decreasing order) the countries according to the level of their own average private expenditure.

Fig. 3 confirms the positive relation between real per-capita income and cultural capital, when the latter is measured as the GDP share of the sum of household and government expenditures on recreation and culture. The figure displays the results for the years $1990-2003$, for 21 countries. ${ }^{12}$

Ireland is not considered in this sample because of its sharp decline in recreation and culture expenditure as a fraction of GDP, mainly due to the intense increase in the GDP of the country in the 1990s. Note that this particular situation makes this country an outlier very clearly observable in Fig. 1, where quite a high GDP per capita (36,703 US dollars in 2007) is related to a relatively low cultural participation rate (59\%).

\footnotetext{
12 Australia, Austria, Belgium, Czech Republic, Denmark, Finland, France, Germany, Greece, Iceland, Italy, Japan, Korea, Netherlands, Norway, Portugal, Slovak Republic, Spain, Sweden, United Kingdom and United States.
} 
After this first look at some available data, we are now ready to introduce our theory and to study quantitatively the main predictions of a two-sector growth model in which human and cultural capital investments are simultaneously possible and where the average cultural capital in the economy generates externalities for the whole productive system. Our model will also contribute to shed new light on the conditions under which an increase of the GDP share of cultural capital may have a positive effect on the level of real per-capita income in the long-run equilibrium.

\section{Human and cultural capital in economic growth: the framework of analysis and the theoretical model}

In industrialized countries an increasing number of goods and services incorporate an intangible added value deriving from design, aesthetics, and symbolic and identity values. Since innovation and intangible values become the distinctive successful factors, for these goods and services competition no longer takes place simply through cost-cutting activities, but instead by means of a more creative (not the less costly) labor force. In this new context, global competition requires not only people with a high level of education, but also (and probably more importantly) with a high level of creativity.

Along these lines Scott (2000) argues that the presence of skilled workers is not a sufficient condition to obtain efficacious patterns of productive employment since it is not only the usual concept of agglomerations of technologically dynamic firms that generate developments in a regional system, but also the existence of qualities such as cultural insight, imagination, and originality created from within the local system of production. The production system and the geographic milieu are therefore just two faces of a single economic and cultural reality represented by dense agglomerated structures of employment and social life. Florida $(2002,2005)$ introduces a new theory of regional economic growth based on the role of the creative class, composed of creative and innovative workers and characterized by high productivity levels. Therefore, according to Florida, economies whose populations (workers) show higher levels of creativity grow faster. Creativity is now considered as a collective process that overcome the Romantic view of creative genius, once regarded as a gift from the gods and therefore extraneous to the determination of the surrounding social context.

In their analysis of Florida's creative capital theory (as opposed to human capital theory), Marlet and van Woerkens (2004) conclude that Florida's creative class is a better standard to measure human capital than education, since "members of the creative class are essentially working, but not necessarily highly educated, while highly educated people are not necessarily doing any work at all" (p. 19).

Human capital, measured by the level of education, is commonly considered one key variable fostering economic growth. In the light of the previous discussion, we believe that this picture has to be completed, our claim being that economic growth depends not only on education but also on creativity. Creative people react more promptly to change: creativity makes the labor-force more productive both for modern and mature firms and stimulates Schumpeterian entrepreneurs in establishing new firms. Furthermore, highly educated and creative people have higher incomes and participate more in all the activities offered to the community, revealing a higher marginal propensity to consume local services, thus sustaining the local economy more effectively. A positive externality effect can also be envisaged since the use of human capital may be more productive where more creative people are working and living together.

If the creative use of skills and knowledge, which are attained by means of education, has an autonomous role the focal point of the discussion then becomes: where does creativity come from? Our answer to this question is that cultural capital is the main source of creativity and that cultural capital accumulation can positively contribute to economic growth via human capital formation.

Until now the possible role played by cultural capital investment in economic growth has been almost completely neglected by growth theory, according to which long-run growth is usually the outcome of the accumulation of factor-inputs, both tangible and intangible, as labor (either skilled or unskilled) and capital (mainly physical, human and technological capital). Our model aims at filling this important gap in the literature by analyzing the predictions of a two-sector growth model in which cultural and human capital can interact complementarily with each other not only in goods production but also in the process leading to agents' skill-acquisition.

\subsection{The production of consumption goods}

Consider a closed economy in which consumption goods (or final output, $Y$ ) are used as the numeraire good $\left(P_{Y}=1\right)$ and produced competitively (the sector is, thus, populated by a very large number of small, atomistic and structurally-identical firms). In order to obtain its own output, the industry's representative firm employs the following Cobb-Douglas technology:

$$
Y_{t}=\beta\left(A_{t} K\right)^{1-\alpha} H_{Y t}^{\alpha}, \quad \beta>0, \alpha \in(0 ; 1), H_{Y t} \equiv u_{t} H_{t}, H_{t} \equiv L h_{t}, u_{t} \in[0 ; 1]
$$

where $A_{t}$ is the aggregate stock of cultural capital available in the economy at $t, K$ denotes the fixed supply of physical capital, $H_{Y t}$ is the fraction of the total amount of human capital devoted to goods production and $\beta$ is a positive technological parameter.

The reason why we take $K$ as constant is that, through the model, we want to focus our attention on the effects of the simultaneous investments in cultural and human capital on the equilibrium, long-run growth rate of the economy.

With cultural capital viewed as the stock of tangible and intangible cultural expressions (Throsby, 2001) and, therefore, having a productive use per se (Throsby, 2008), we can think of the total stock of human capital $\left(H_{t}\right)$ as the number of 
workers, $L$, times the average level of quality (i.e., the number of years of schooling) of each worker, $h_{t}$. We postulate that each individual in the population works and supplies inelastically one unit of labor-services per unit of time. Hence, population size coincides with the number of workers (or labor-force). Because we are not interested in modeling population dynamics, we assume that $L$ is also constant and, for the sake of simplicity, normalize it to one $\left(L_{t}=L_{0} \equiv 1, \forall t\right)$. Under these assumptions, we clearly have $H_{t}=h_{t}$ at each time, implying that $H_{t}$ can grow only because of improvements in the average level of quality (the number of years of schooling) of each individual, $h_{t}$. In this economy the available stock of knowledge embodied in humans (that is to say the available stock of human capital, $H_{t}$ ) can be either employed (in the proportion $u_{t}$ ) in the goods-production sector, or (in the proportion $1-u_{t}$ ) in the education-sector, where the increase of the average level of quality of each individual in the population can take place. Variable $u_{t} \in[0 ; 1]$ is endogenous and along the balanced growth path (BGP, henceforth) equilibrium, to be defined more formally in a moment, it will turn out to be also constant (i.e., $\left.u_{t}=u, \forall t\right)$.

The specification of the aggregate production function (Eq. (1)) implies that $A$ and $K$ are perfect substitutes in production, in the sense that only their combination $A K$ matters for output manufacture. Moreover, according to the same equation, if not only $K$ but also $A$ were fixed, since production human capital $H_{Y}$ displays diminishing marginal returns in the production sector, the economy would be doomed to zero economic growth in the very long run. If, instead, $A$ rose along with $H_{Y}$ (as we suppose in what follows), then the aggregate production function would specify constant returns to scale in $A$ and $H_{Y}$ together, for fixed $K$. As a result, in this case the economy would be capable of endogenous growth. Since $K$ is constant, for convenience we can set $K=1$ throughout the paper and, hence, rewrite Eq. (1) as:

$$
Y_{t}=\beta A_{t}^{1-\alpha} H_{Y t}^{\alpha}, \quad \beta>0, \alpha \in(0 ; 1), H_{Y t} \equiv u_{t} H_{t}, H_{t} \equiv L h_{t}, u_{t} \in[0 ; 1]
$$

In $\left(1^{\prime}\right), \alpha$ and $(1-\alpha)$ denote respectively the human and cultural capital shares in aggregate GDP. The representative firm operating in the final output sector is so small that it takes $\beta$ as given. ${ }^{13}$ Thus, this parameter represents the economy-wide level of technology, common to each firm producing goods.

Even though it is taken as a constant by each single firm producing consumption goods, we postulate that the common level of technology $(\beta)$ depends on some function of the relative intensity of cultural capital at the economy-wide level (the ratio of the aggregate cultural to human capital stock, $\left.A_{t} / H_{t}\right)$ and assume that the function linking $\beta$ to $A_{t} / H_{t}$ is non-linear, that is:

$$
\beta \equiv\left(\frac{A_{t}}{H_{t}}\right)^{\phi}, \quad \phi \neq \alpha, \phi \neq 0 .
$$

The ratio $\frac{A_{t}}{H_{t}}$ is another relevant endogenous variable of this model and can also be interpreted as a measure of the economy's average cultural capital (cultural capital, $A$, per unit of human capital, $H$ ). Along the BGP equilibrium this ratio will also be constant (and, clearly, positive). Notice that, in order to have the most general possible model, in Eq. ( $\left.1^{\prime \prime}\right)$ we do not impose any constraint on the parameter $\phi$, except that it should be different from $\alpha{ }^{14}$ The reason behind this assumption is that, as we shall show in a moment (Eq. (2)), when $\phi<\alpha$ an increase in the stock of cultural capital $\left(A_{t}\right)$ always reduces, ceteris paribus, the productivity of cultural capital in goods production (this can be seen as a negative congestion externality due, as an example, to the fact that cultural capital is already so abundant in the economy that a further increase of it reduces unambiguously its own productivity in the goods sector). Instead, when $\phi>\alpha$ an increase in the aggregate stock of cultural capital in the economy $\left(A_{t}\right)$ always increases, ceteris paribus, the productivity of cultural capital in the sector producing consumption goods (unlike the previous case, this can be seen as a positive capital-rationing externality, due to the fact that now cultural capital might be so scarce in the economy that an increase of it unambiguously causes its own productivity in manufacturing activity to rise). With $\phi \neq \alpha$ we are able to capture, within the same setting, these two different situations and $\phi$ can be, thus, regarded as a parameter measuring the strength of the two distinct types of externalities we try to model simultaneously in the paper.

By combining $\left(1^{\prime}\right)$ and $\left(1^{\prime \prime}\right)$, the aggregate technology for goods production reads finally as:

$$
Y_{t}=\left(\frac{A_{t}}{H_{t}}\right)^{\phi} A_{t}^{1-\alpha} H_{Y t}^{\alpha}, \quad \beta>0, \alpha \in(0 ; 1), H_{Y t} \equiv u_{t} H_{t}, H_{t} \equiv L h_{t}, u_{t} \in[0 ; 1], \phi \neq \alpha, \phi \neq 0 .
$$

When $\phi \neq 0$, since it is constant in equilibrium, the term $A_{t} / H_{t}$ suggests that goods production tends to become more and more cultural-capital intensive through time as the total stock of human capital in the economy increases.

Because consumption goods are produced competitively, maximization of the representative firm's instantaneous profit function implies:

$$
p_{A t} \equiv \frac{\partial Y_{t}}{\partial A_{t}}=\beta(1-\alpha)\left(\frac{H_{Y t}}{A_{t}}\right)^{\alpha}=(1-\alpha) u_{t}^{\alpha}\left(\frac{A_{t}}{H_{t}}\right)^{\phi-\alpha}
$$

\footnotetext{
13 The representative firm is, indeed, unable to affect the economy-wide neutral technological progress. For this reason it takes $\beta$ as a given positive constant.

14 If $\phi=0, \beta$ would equal 1 . We neglect this over-simplified case, too.
} 


$$
w_{t} \equiv \frac{\partial Y_{t}}{\partial H_{Y t}}=\beta \alpha\left(\frac{A_{t}}{H_{Y t}}\right)^{1-\alpha}=\frac{\alpha}{u_{t}^{1-\alpha}}\left(\frac{A_{t}}{H_{t}}\right)^{1+\phi-\alpha},
$$

where $p_{A t}$ and $w_{t}$ denote, respectively, the marginal productivities of cultural and human capital in goods production at time $t$ (i.e., the marginal contributions of one more unit of cultural/human capital to GDP formation). In this respect, while $w$ represents the wage rate per unit of human capital, $p_{A}$ can be taken as indicative of the shadow price of cultural capital in terms of goods. As already mentioned, the effect of an increase in the stock of cultural capital $(A)$ on its shadow price $\left(p_{A}\right)$ is non-monotonic since, for each $\alpha \in(0 ; 1), u \in(0 ; 1), A>0$ and $H>0$, it can be either positive or negative depending on whether $\phi$ is greater or lower than $\alpha$, respectively. Later on we shall see that the relative size of $\phi$ with respect to $\alpha$ also plays a major role in the analysis of the effects of changes of the cultural capital share in aggregate GDP on per-capita real income.

After describing the production side of the economy, we can now analyze the consumers' behavior.

\subsection{Consumers' behavior}

The economy's stationary population is made of many identical households. Hence, we can concentrate on the consumption behavior of a single dynastic family. Since physical capital $(K)$ is in fixed supply and cannot be reproduced, we assume that the representative household uses all the income it does not consume just for cultural capital investment purposes. Thus:

$$
\dot{A}_{t}=Y_{t}-C_{t}-\delta_{A} A_{t}, \quad \delta_{A} \geq 0, A_{0}>0,
$$

where $\dot{A}_{t}$ represents net cultural capital investment, $C_{t}$ is consumption and $\delta_{A}$ is the constant instantaneous depreciation rate of cultural capital. ${ }^{15}$ The above equation says that savings $\left(Y_{t}-C_{t}\right)$ are all employed to accumulate (gross) cultural capital, $\dot{A}_{t}+\delta_{A} A_{t}$. Using (2) and (3), the previous equation can also be written as:

$$
\dot{A}_{t}=\left(p_{A t}-\delta_{A}\right) A_{t}+w_{t} H_{Y t}-C_{t}, \quad Y_{t}=p_{A t} A_{t}+w_{t}(\underbrace{u_{t} H_{t}}_{\equiv H_{Y t}}) .
$$

As already mentioned, the fraction $u$ of the available stock of human capital $(H)$ is devoted to production activities, and the remaining portion $(1-u)$ of $H$ is, instead, used to produce new human capital (new knowledge embodied in individuals through education). The law of motion of human capital is postulated to be:

$$
\dot{H}_{t}=\sigma\left(1-u_{t}\right) H_{t}+\left(\varphi \gamma_{A t}\right) H_{t}, \quad H_{0}>0, \sigma>0, \varphi \in(0 ; 1) .
$$

In (5) $\sigma$ is the productivity of human capital employed in educational activity and $\varphi$ reflects the impact of the growth rate of cultural capital $A\left(\gamma_{A_{t}} \equiv \dot{A}_{t} / A_{t}\right)$ on the accumulation of $H$. Since $\varphi \in(0 ; 1)$, this parameter can be interpreted as a measure of the degree of complementarity between human and cultural capital investments. Thus, Eq. (5) formalizes the idea that investment in cultural capital may be beneficial to human capital accumulation and suggests that skill acquisition occurs not only through formal education (i.e., an increase of the number of years of schooling), but also through an adequate supply in the economic system as a whole of culture-based goods. So, while the university education increases someone's embodied knowledge and her/his probability of developing a good career, it is certainly not the only reliable path towards a successful future, as for instance Microsoft founder Bill Gates testifies.

As reported in Sacco and Segre (2009), there are examples that support the view that culture and human capital investments may well be linked by a relation of complementarity. Throughout history, science, math and technology have flourished only where and when all the arts have flourished. In the same direction, a study of 150 biographies of great inventors - from Pasteur to Einstein - demonstrates that nearly all of the eminent scientists were also musicians, artists, writers or poets. Several recent studies reveal that exposure to and participation in the arts strengthens children's educational performance. A nine-month study of three-year-old children showed that early training in singing and playing musical instruments stimulates the brain in pre-school children and enhances learning. Moreover, college student test scores were higher when students listened to ten minutes of Mozart's piano music immediately prior to taking an IQ test.

Simple inspection of equations ( $\left.1^{\prime \prime \prime}\right)$ and (5) reveal the two main differences between our model and that of Uzawa (1965) and Lucas (1988). The first difference concerns the way the economy-wide level of technology is modeled in the two approaches. While Uzawa and Lucas regard this variable as an exogenous one, in our model $\beta$, although constant, is endogenously determined. Moreover, it is modeled in the form of an externality (a non-linear function of the economy's average cultural capital) that the single firm fails to take into account, but that plays a relevant role at the aggregate production level. The second difference consists in postulating a technology for human capital formation in which a faster growth of cultural capital (higher $\gamma_{A t}$ ) accelerates, ceteris paribus, the rate at which human capital accumulates over time,

$\overline{15}$ It is well known that cultural heritage and artistic works might need continuous conservation and maintenance expenditures. These are caught by $\delta_{A}$. 
$\gamma_{H t} \equiv \dot{H}_{t} / H_{t}$. This equation formally describes the empirical evidence quoted in Section 2 according to which artistic consumption may result in stronger education attainments. In other words, we claim that human capital accumulation depends not only on the fraction of the total stock of this factor-input employed in the education system, $(1-u) H$, but also on cultural capital investment, our argument being that investing in cultural capital enables people to accumulate human capital faster.

For given $\sigma>0$ and $u \in(0,1)$, the constraint $\varphi \in(0 ; 1)$ prevents the growth rate of the model's variables from either exploding $(\varphi=1)$ or being negative $(\varphi>1)$ along a BGP equilibrium where $A_{t} / H_{t}$ remains time-invariant (complementarity hypothesis). On the other hand, if $\varphi=0$ we end up with the same human capital accumulation technology of Uzawa (1965) and Lucas (1988). This possibility is explicitly ruled out in equation Eq. (5) by the fact that $\varphi$ is assumed to be strictly positive.

The main novelty of the approach presented here resides in the fact that growth of cultural capital acts in this framework as a mechanism of endogenous appreciation of human capital stock in the equation of skill-supply: cultural and human capital investments are complementary for each other in the process of skill acquisition since in the long run an increase in $\gamma_{A}$, and thus in $A_{t}$, stimulates human capital investment $\left(\dot{H}_{t}\right)$ and its growth rate $\left(\gamma_{H}\right)$, ultimately leading to a rise of $H_{t}$, as well.

Given $\dot{H}_{t}$, the problem of the representative household can be recast as:

$$
\begin{aligned}
& \operatorname{Max}_{\left\{C_{t}, u_{t}, A_{t}, H_{t}\right\}_{t=0}^{\infty}} \mathrm{U} \equiv \int_{0}^{\infty}\left(\frac{C_{t}^{1-\theta}-1}{1-\theta}\right) \mathrm{e}^{-\rho t} \mathrm{~d} t, \quad \rho>0, \theta>1, \quad \frac{\dot{L}_{t}}{L_{t}}=0, \quad L_{0} \equiv 1 \\
& \text { s.t.: } \dot{A}_{t}=\left(p_{A t}-\delta_{A}\right) A_{t}+w_{t}\left(u_{t} H_{t}\right)-C_{t}, \quad u_{t} \in[0 ; 1] \forall t, \delta_{A} \geq 0, \quad H_{Y t} \equiv u_{t} H_{t} \\
& \dot{H}_{t}=\sigma\left(1-u_{t}\right) H_{t}+\left(\varphi \gamma_{A t}\right) H_{t}, \quad \sigma>0, \varphi \in(0 ; 1) . \\
& \lim _{t \rightarrow \infty} \lambda_{A t} A_{t}=0, \quad \lim _{t \rightarrow \infty} \lambda_{H t} H_{t}=0 \\
& A_{0}, H_{0}>0 .
\end{aligned}
$$

We denoted by $\rho$ the pure rate of time preference, by $1 / \theta$ the intertemporal elasticity of substitution in consumption and by $\lambda_{A}$ and $\lambda_{H}$ the co-state variables associated, respectively, to cultural and human capital investments. The assumption $\rho>0$ ensures that $U$ is bounded away from infinity if $C$ is constant and finite over time. The hypothesis $\theta>1$ is, instead, dictated by available evidence (see especially Hall, 1988 and, more recently, Growiec, 2006, pp. 17-19, for a concise survey).

\subsection{The effects of cultural capital on economic growth}

In order to develop our analysis of the effects of cultural capital on economic growth, we focus on a BGP equilibrium where:

(i) The growth rate of all time-dependant variables is constant (and possibly positive);

(ii) The ratio $A_{t} / H_{t}$ remains invariant over time.

Eqs. (5), (2) and (3) suggest that $u, p_{A}$ and $w$ are all constant along the BGP equilibrium.

Proposition 1 (Characterization of the BGP Equilibrium). Along the BGP equilibrium:

$$
\begin{aligned}
& \gamma_{C}=\gamma_{A}=\gamma_{H}=\gamma_{Y} \equiv \gamma=\left(\frac{\sigma-\rho}{\theta-\varphi}\right) \\
& u=\frac{\sigma(\theta-1)+\rho(1-\varphi)}{\sigma(\theta-\varphi)} \\
& p_{A}=\frac{\theta\left(\sigma+\delta_{A}\right)-\varphi\left(\rho+\delta_{A}\right)}{(\theta-\varphi)} \\
& \left(\frac{A_{t}}{H_{t}}\right)=\left\{\left[\frac{\theta\left(\sigma+\delta_{A}\right)-\varphi\left(\rho+\delta_{A}\right)}{(1-\alpha)(\theta-\varphi)}\right]^{\frac{1}{\alpha}} \cdot \frac{\sigma(\theta-\varphi)}{\sigma(\theta-1)+\rho(1-\varphi)}\right\}^{\frac{\alpha}{\phi-\alpha}} .
\end{aligned}
$$

Proof. See Appendix A.

Eq. (8) gives the common balanced-growth rate of the main variables of the model (respectively, consumption, cultural capital, human capital, and income). Eq. (9) represents the share of human capital devoted in equilibrium to production activity and Eqs. (10) and (11) provide, respectively, the equilibrium shadow price of cultural capital and the equilibrium ratio of cultural to human capital.

With our parameter values, ${ }^{16}$ it is possible to show that $\sigma>\rho$ is sufficient to guarantee that the household's problem has an interior solution $(0<u<1),{ }^{17}$ and that the equilibrium values of the other relevant variables of the model $\left(\gamma, p_{A}\right.$

\footnotetext{
16 In particular, $\sigma>0, \varphi \in(0 ; 1), \delta_{A} \geq 0, \theta>1, \rho>0$ and $\alpha \in(0 ; 1)$.

17 This implies that human capital is always used simultaneously in the sector producing final goods and in the education sector.
} 
and $A_{t} / H_{t}$ ) are all strictly positive. Therefore, in what follows we assume that, in addition to the other parameter values, the condition $\sigma>\rho$ is always checked. This condition requires that the productivity of human capital employed in the education sector is sufficiently large compared with the subjective discount rate. ${ }^{18}$ Moreover, note that (since $\theta$ is greater than $\varphi$ ) when the condition $\sigma>\rho$ is checked it follows that $p_{A}$ (the shadow price of cultural capital in terms of goods) is larger than one and, therefore, surely positive.

As a final comment it is possible to observe that the parameter $\phi$ (a measure of the strength of externalities coming from the average cultural capital in the economy) affects solely the $A_{t} / H_{t}$ ratio along the BGP equilibrium and that ( $\left.1-\alpha\right)-i . e$, the share of cultural capital in aggregate GDP - has solely level effects, as it affects neither economic growth, nor the sectoral distribution of human capital, nor the shadow-price of cultural capital. We can now formally state the main results of the model.

Proposition 2 (The Role of Complementarity Between Cultural and Human Capital Accumulations in Economic Growth). Provided that $\sigma>\rho$, along the BGP equilibrium economic growth depends positively on the parameter $(\varphi)$ measuring the degree of complementarity between cultural and human capital investments.

Proof. Immediate from Eq. (8).

In words, Proposition 2 says that along the BGP the more complementary for each other the investments in the two forms of capital are, the higher the growth rate of real per-capita income is. In terms of policy suggestions, this result can be interpreted as indicating that culture and creativity should be part of the training program of schools and also of continuous education programs. As an example, it seems to be consistent with this policy prescription the fact that in 2002 the Los Angeles County Board of Supervisors decided that sequential instruction in the multiple arts disciplines would be scheduled into each school day and accounted for in the budget of every county school district.

Another result of the model is related to the effects of cultural capital depreciation deriving either from physical deterioration of tangible goods or from loss of intangible values.

Proposition 3 (The Role of Cultural Capital Depreciation in Economic Growth). Along the BGP equilibrium, economic growth is independent of the rate of cultural capital depreciation $\left(\delta_{A}\right)$.

Proof. Immediate from Eq. (8).

To see why economic growth is totally independent of cultural capital depreciation, notice that $\gamma$ can also be recast as:

$$
\gamma=\left(\frac{\sigma-\rho}{\theta \sigma-\varphi \rho}\right)\left(p_{A}-\delta_{A}\right) .
$$

Accordingly, $\frac{\partial \gamma}{\partial \delta_{A}}=\left(\frac{\sigma-\rho}{\theta \sigma-\varphi \rho}\right)(\underbrace{\frac{\partial p_{A}}{\partial \delta_{A}}}_{=1}-1)=0$.

In sum, $\delta_{A}$ can affect economic growth both directly (through the term $-\delta_{A}$ in Eq. (12)) and indirectly (through $p_{A}$ ). However, these two effects have opposite signs and the same magnitude and, therefore, they exactly cancel each other out. The conclusion is that in equilibrium changes in the depreciation rate of cultural capital will exert no impact on the growth rate of real per capita income.

\subsection{The effects of cultural capital on the level of GDP}

Our model can also be used to investigate the relation between the cultural capital share in GDP and the level of real per-capita income.

Proposition 4 (The Effect of a Change of the Cultural Capital Share in GDP on the Level of Real per Capita Income). Along the BGP equilibrium the effect of a change in the GDP share of cultural capital on the level of real per-capita income, i.e. the sign of $\frac{\partial Y_{t}}{\partial(1-\alpha)}$, is non-monotonic and crucially depends on whether $\phi$ (the parameter measuring the strength of externalities from average cultural capital in the economy, $\left.A_{t} / H_{t}\right)$ is higher or lower than $\alpha$. In particular,

- When $\phi>\alpha$ (capital-rationing externality), then $\frac{\partial Y_{t}}{\partial(1-\alpha)}<0$ without any ambiguity;

18 Imposing $\sigma>\rho$ is quite standard in growth models with two state variables (see, among others Arnold, 1998, p. 85; Strulik, 2005, p. 135 and Bucci, 2008, p. 1136 for growth models with endogenous human and technological capital accumulation). 
- When $\frac{\eta-\sqrt{\eta^{2}+4 \varepsilon}}{2}<\phi<\frac{\eta+\sqrt{\eta^{2}+4 \varepsilon}}{2}<\alpha$ (congestion externality), the condition:

$$
\ln \left(\frac{p_{A}}{1-\alpha}\right)<\frac{(1+\phi-\alpha)(\alpha-\phi)}{(1-\alpha)}+\phi \ln (u)
$$

ensures that $\frac{\partial Y_{t}}{\partial(1-\alpha)}>0$, where $\eta \equiv(2 \alpha-1)+(1-\alpha) \ln (u)$ and $\varepsilon \equiv \alpha(1-\alpha)$.

Proof. See Appendix B.

In words Proposition 4 says that in this economy a rise of the share of cultural capital in GDP $(1-\alpha)$ may have over the very long run a positive effect on real per-capita income $(Y)$ provided that: (i) cultural capital produces congestion externalities $(\phi<\alpha)$-as already mentioned, this might for instance occur whenever $A$ is sufficiently abundant that a further increase of it leads, ceteris paribus, to a reduction of its productivity in goods production, and; (ii) the shadow-price $\left(p_{A}\right)$ of cultural capital is lower than a ceiling. If, instead, cultural capital produces capital-rationing externalities $(\phi>\alpha)-$ contrary to the previous situation this might happen, for example, when $A$ is so scarce in aggregate that an increase of it contributes, ceteris paribus, to a rise of its productivity in manufacturing activity - the effect of an increase of its share in total GDP on real per capita income is unambiguously negative. As a whole, this result seems (indirectly) to suggest that for an expansion of the GDP-share of cultural capital to affect positively real per capita income the stock of $A$ already existing in the economy should be higher than a threshold ${ }^{19}$ (such that, as a pre-requisite, $\partial p_{A t} / \partial A_{t}<0$ is checked). This is consistent with the belief that culture has an addictive-good nature, in the sense that (due to its high costs of activation) a certain minimal degree of cultural capital diffusion is crucial for it to produce positive long-run effects. ${ }^{20}$

Another way to assess the result of Proposition 4 is to think in terms of the existence of a threshold involving not the existing stock of $A$, but (more directly) its share in total GDP, namely $(1-\alpha)$. In this sense, we conclude that if $(1-\alpha)<(1-\phi),{ }^{21}$ and the shadow-price of cultural capital is sufficiently low, then a further increase of $(1-\alpha)$ can lead to a higher per-capita income. On the other hand, if the GDP-share of cultural capital is already large, ${ }^{22}$ expanding it further will definitely cause a fall of $Y$ along the BGP equilibrium. So, in general, we infer that the relation going from the GDP-share of cultural capital to per-capita GDP may be inverse- $U$ shaped in our model economy.

Despite the way we interpret it, the main result of the proposition remains that the effects of a change of $(1-\alpha)$ on $Y$ are non-monotonic. To convey the economic (and algebraic) intuition of this result, we write $Y_{t}$ as follows (see Eq. (4)):

$$
Y_{t}=p_{A t} A_{t}+w_{t}\left(u H_{t}\right)
$$

Using Eqs. (2) and (3) it is possible to show that:

$$
\begin{aligned}
\frac{\partial p_{A t}}{\partial A_{t}} & =(1-\alpha) u^{\alpha}\left(\frac{A_{t}}{H_{t}}\right)^{\phi-\alpha} \frac{(\phi-\alpha)}{A_{t}} \\
\frac{\partial w_{t}}{\partial A_{t}} & =\frac{\alpha}{u^{1-\alpha}}\left(\frac{A_{t}}{H_{t}}\right)^{1+\phi-\alpha} \frac{(1+\phi-\alpha)}{A_{t}} .
\end{aligned}
$$

For given $\alpha \in(0 ; 1), u \in(0 ; 1), A_{t}>0$ and $H_{t}>0$, when $\phi>\alpha$ (the capital-rationing externalities case) the two derivates written above are both positive. This means that, following an increase of $A_{t}, Y_{t}$ would ceteris paribus surely rise (in part because $A_{t}$ increases and in part because $p_{A t}$ and $w_{t}$ also grow up). In turn, $p_{A t} A_{t}$ can also be recast as:

$$
p_{A t} A_{t}=s Y_{t}
$$

where $s$ is the share of cultural capital in income $\left(s \equiv \frac{p_{A t} A_{t}}{Y_{t}}=1-\alpha\right)$. Plugging the last expression into the one for $Y_{t}$ leads to:

$$
(1-s) Y_{t}=w_{t}\left(u H_{t}\right) \text {. }
$$

When $\phi>\alpha$, the RHS of the equation above increases when $A_{t}$ goes up. With $Y_{t}$ being also rising in $A_{t}$, the LHS would (without any ambiguity) go up if $s$ diminished. This is the negative relationship between $s$ and $Y_{t}$ we find whenever $\phi>\alpha$ applies.

Suppose, instead, that $\phi<\alpha$ (the congestion externalities case). We see that, for given $\alpha \in(0 ; 1), u \in(0 ; 1), A_{t}>0$ and $H_{t}>0$ :

$$
\frac{\partial p_{A t}}{\partial A_{t}}=(1-\alpha) u^{\alpha}\left(\frac{A_{t}}{H_{t}}\right)^{\phi-\alpha} \frac{(\phi-\alpha)}{A_{t}}<0
$$

\footnotetext{
19 Since our model has two state variables, we cannot determine analytically this threshold level of $A$.

20 See Sacco and Segre (2009) for a more extensive discussion on this point.

21 This is equivalent to assuming $\phi<\alpha$.

22 That is, $(1-\alpha)>(1-\phi)$ applies.
} 
whereas the sign of $\frac{\partial w_{t}}{\partial A_{t}}$ is now ambiguous. Clearly, $Y_{t}$ can always be written either as:

$$
Y_{t}=p_{A t} A_{t}+w_{t}\left(u H_{t}\right)
$$

or as:

$$
(1-s) Y_{t}=w_{t}\left(u H_{t}\right)
$$

From the first equality we see that, following an increase of $A_{t}$, the final effect on income $\left(Y_{t}\right)$ is totally ambiguous. From the second condition, instead, we conclude that, following the same rise of $A_{t}, s$ could either augment or diminish for this condition to continue to be checked. In sum, the relation between $s$ and $Y_{t}$ is a priori completely ambiguous when $\phi<\alpha$. However, in this case Proposition 4 provides a formal condition for an increase of the cultural capital share in GDP to produce an unambiguously positive effect on real per capital income.

Fig. 3 shows an overall positive correlation between a possible measure of aggregate cultural capital (i.e., total expenditures on recreation and culture), as a share of GDP, and GDP per capita. In the terms of our theoretical model, the data plotted in Fig. 3 point to a positive correlation between $(1-\alpha)$ and $Y$. According to the model, this should be interpreted as the indication that, for the 21 countries considered in the sample over the period 1990-2003, the two conditions:

$$
\frac{\eta-\sqrt{\eta^{2}+4 \varepsilon}}{2}<\phi<\frac{\eta+\sqrt{\eta^{2}+4 \varepsilon}}{2}<\alpha, \quad \eta \equiv(2 \alpha-1)+(1-\alpha) \ln (u) ; \varepsilon \equiv \alpha(1-\alpha)
$$

and

$$
\ln \left(\frac{p_{A}}{1-\alpha}\right)<\frac{(1+\phi-\alpha)(\alpha-\phi)}{(1-\alpha)}+\phi \ln (u)
$$

are satisfied.

Clearly, the simple representation of the available data about cultural capital we gave in Section 2 is not at the moment enough to derive any further conclusion on the causal relation between cultural capital share in GDP and real per capital income and on whether the requirements identified above are actually met or not. These concerns justify the need for further research on this issue in the future, especially at the empirical level.

\section{Concluding remarks}

In industrialized countries competition no longer takes place simply through cost-cutting since product innovation represents a distinctive successful factor and an increasing number of goods and services incorporate an intangible added value arising from design, aesthetics, and symbolic values. Creativity, now considered as a collective process that overcomes the Romantic view of creative genius, and a talented labor force are essential drivers of economic growth. In such a framework, because cultural insight, imagination, and originality (whose main source is culture) become increasingly important, the simple use of knowledge (embodied in humans and attained through formal education) is no more sufficient to obtain efficacious patterns of productive employment and long-run, sustainable economic growth.

By defining culture according to Throsby's (2001) definition of cultural capital (i.e., an asset of tangible and intangible cultural expressions), in this paper we analyzed one possible channel through which this variable may positively affect percapita income growth. At this aim we built a two-sector endogenous growth model where two different types of capital (human and cultural capital) can be accumulated over time. Since physical capital is assumed to be in fixed supply, the representative household uses all the income it does not consume just for cultural capital investment purposes. The first conclusion of the model is that the more cultural and human capital investments are complementary for each other, the higher the equilibrium growth rate of real per-capita income is over the long run. Moreover, we have also investigated the conditions for an increase of the cultural capital share in GDP to have a positive effect on real per capita income, namely that the stock of cultural capital existing at the economy-wide level produces congestion externalities and that there exists an upper-bound to its shadow-price.

We think that the present analysis might be used as a basis for future empirical and theoretical works. Empirically, it would be of particular interest to analyze whether the two requirements just mentioned are in fact satisfied or not. From the theoretical point of view, instead, a very promising field of further research would be the development of a more sophisticated growth model capable of explaining the mechanics of the complementarity relationship between investment in cultural capital and access to skill-acquisition.

\section{Appendix A. Eqs. (8)-(11) in the text}

The Hamiltonian function $\left(J_{t}\right)$ associated with the dynamic optimization problem of the representative household is:

$$
J_{t}=\left(\frac{C_{t}^{1-\theta}-1}{1-\theta}\right) \mathrm{e}^{-\rho t}+\lambda_{A t}\left[\left(p_{A t}-\delta_{A}\right) A_{t}+w_{t}\left(u_{t} H_{t}\right)-C_{t}\right]+\lambda_{H t}\left[\sigma\left(1-u_{t}\right) H_{t}+\left(\varphi \gamma_{A t}\right) H_{t}\right] .
$$

Households are competitive in that, in solving for the optimal paths of $\left\{C_{t}, u_{t}, A_{t}, H_{t}\right\}_{t=0}^{\infty}$, each of them takes prices ( $p_{A t}$ and $\left.w_{t}\right)$ and the growth rate of aggregate cultural capital $\left(\gamma_{A t}\right)$ as given at each point in time. The (necessary) first order 
conditions associated to the Hamiltonian function written above read, thus, as:

$$
\begin{aligned}
\frac{\partial J_{t}}{\partial C_{t}} & =0 \Leftrightarrow \frac{\mathrm{e}^{-\rho t}}{C_{t}^{\theta}}=\lambda_{A t} \\
\frac{\partial J_{t}}{\partial u_{t}} & =0 \Leftrightarrow \lambda_{A t}=\left(\frac{\sigma}{w_{t}}\right) \lambda_{H t} \\
\frac{\partial J_{t}}{\partial A_{t}} & =-\dot{\lambda}_{A t} \Leftrightarrow \lambda_{A t}\left(p_{A t}-\delta_{A}\right)=-\dot{\lambda}_{A t} \\
\frac{\partial J_{t}}{\partial H_{t}} & =-\dot{\lambda}_{H t} \Leftrightarrow \lambda_{A t} u_{t} w_{t}+\lambda_{H t}\left[\sigma\left(1-u_{t}\right)+\varphi \gamma_{A t}\right]=-\dot{\lambda}_{H t} .
\end{aligned}
$$

Along the BGP equilibrium all time-dependant variables grow at a constant rate and, therefore, $u$ is also constant. Combining (A.2) and (A.4) and using (A.3) yield, respectively

$$
\begin{aligned}
& \frac{\dot{\lambda}_{H t}}{\lambda_{H t}}=-\left(\sigma+\varphi \gamma_{A}\right) \\
& \frac{\dot{\lambda}_{A t}}{\lambda_{A t}}=-\left(p_{A t}-\delta_{A}\right) .
\end{aligned}
$$

Eq. (A.2) also implies

$$
\frac{\dot{\lambda}_{A t}}{\lambda_{A t}}=\frac{\dot{\lambda}_{H t}}{\lambda_{H t}}-\gamma_{w}, \quad \text { where } \gamma_{w} \equiv \dot{w}_{t} / w_{t} \text { denotes the growth rate of wages }\left(w_{t}\right) .
$$

Plugging $\left(A .3^{\prime}\right)$ and (A.5) into (A.2') gives:

$$
p_{A t}=\left(\sigma+\delta_{A}\right)+\varphi \gamma_{A}+\gamma_{w} .
$$

From (2) and (3) in the main text, it follows that along the BGP equilibrium (where $A_{t}$ and $H_{t}$ grow at the same constant rate, $\gamma_{A}=\gamma_{H} \equiv \gamma$, and $u$ is constant) $p_{A}$ and $w$ are both constant. In particular, the constancy of $w$ (i.e., $\gamma_{w}=0$ ) implies:

$$
p_{A t}=\left(\sigma+\delta_{A}\right)+\varphi \gamma=p_{A} .
$$

Equalization of $\left(A .6^{\prime}\right)$ and $(2)$ in the main text leads to:

$$
\left(\frac{u H_{t}}{A_{t}}\right)=\left[\frac{\sigma+\delta_{A}+\varphi \gamma}{\beta(1-\alpha)}\right]^{1 / \alpha}=\left[\frac{p_{A}}{\beta(1-\alpha)}\right]^{1 / \alpha}, \quad \beta \equiv\left(\frac{A_{t}}{H_{t}}\right)^{\phi} .
$$

Recall that the representative firm producing consumption goods takes $\beta$ as given and, in turn, the representative household takes $p_{A}$ as given, too. Using (A.1), $\left(A .3^{\prime}\right)$ and $\left(A .6^{\prime}\right)$ yields:

$$
\frac{\dot{C}_{t}}{C_{t}} \equiv \gamma_{C}=\frac{1}{\theta}[(\sigma-\rho)+\varphi \gamma]
$$

From $\left(A .3^{\prime}\right)$ and (4) in the main text, one obtains:

$$
\frac{\dot{\lambda}_{A t}}{\lambda_{A t}}=-\gamma+w u \frac{H_{t}}{A_{t}}-\frac{C_{t}}{A_{t}} .
$$

Instead, by combining (5) in the main text and (A.5) above, we get

$$
\frac{\dot{\lambda}_{H t}}{\lambda_{H t}}=-\gamma-\sigma u \text {. }
$$

Since $\gamma_{w}=0$, from $\left(A .2^{\prime}\right)$

$$
\frac{\dot{\lambda}_{A t}}{\lambda_{A t}}=\frac{\dot{\lambda}_{H t}}{\lambda_{H t}}
$$

and, then, by equating (A.9) and (A.10):

$$
\frac{C_{t}}{A_{t}}=w u \frac{H_{t}}{A_{t}}+\sigma u
$$

With $w, u$ and $A_{t} / H_{t}$ constant along the BGP equilibrium, Eq. (A.11) - together with (1') and (5) - implies:

$$
\gamma_{C}=\gamma_{A}=\gamma_{H}=\gamma_{Y} \equiv \gamma=\sigma(1-u)+\varphi \gamma \Rightarrow \gamma=\frac{\sigma(1-u)}{(1-\varphi)} \text {. }
$$


With $\gamma_{C}=\gamma_{A} \equiv \gamma$, from (A.8) it follows:

$$
\gamma=\frac{\sigma-\rho}{\theta-\varphi} \text {. }
$$

To find out $(1-u)$, we equate (A.12) and (A.13) and obtain:

$$
(1-u)=\frac{(\sigma-\rho)(1-\varphi)}{\sigma(\theta-\varphi)},
$$

or:

$$
u=\frac{\sigma(\theta-1)+\rho(1-\varphi)}{\sigma(\theta-\varphi)} .
$$

By combining $\left(A .6^{\prime}\right)$ and (A.13) one gets:

$$
p_{A}=\left(\sigma+\delta_{A}\right)+\varphi \gamma=\frac{\theta\left(\sigma+\delta_{A}\right)-\varphi\left(\rho+\delta_{A}\right)}{(\theta-\varphi)} .
$$

Given $p_{A}$ and $u$, from (A.7) we finally obtain:

$$
\begin{aligned}
\frac{H_{t}}{A_{t}} & =\left[\frac{p_{A}}{\beta(1-\alpha)}\right]^{1 / \alpha}\left(\frac{1}{u}\right)=\left[\frac{p_{A}}{(1-\alpha)\left(\frac{A_{t}}{H_{t}}\right)^{\phi}}\right]^{1 / \alpha}\left(\frac{1}{u}\right) \\
& \Rightarrow \frac{A_{t}}{H_{t}}=\left[\left(\frac{p_{A}}{1-\alpha}\right)^{1 / \alpha} \cdot \frac{1}{u}\right]^{\frac{\alpha}{\phi-\alpha}}=\left\{\left[\frac{\theta\left(\sigma+\delta_{A}\right)-\varphi\left(\rho+\delta_{A}\right)}{(1-\alpha)(\theta-\varphi)}\right]^{\frac{1}{\alpha}} \cdot \frac{\sigma(\theta-\varphi)}{\sigma(\theta-1)+\rho(1-\varphi)}\right\}^{\frac{\alpha}{\phi-\alpha}} .
\end{aligned}
$$

\section{Appendix B. Proof of Proposition 4}

Using Eq. (A.7') in Appendix A gives:

$$
A_{t}=\left(\frac{p_{A}}{1-\alpha}\right)^{\frac{1}{\phi-\alpha}} u^{-\frac{\alpha}{\phi-\alpha}} H_{t} .
$$

From Eq. $\left(1^{\prime \prime \prime}\right)$ in the main text:

$$
Y_{t}=\left(\frac{A_{t}}{H_{t}}\right)^{\phi} A_{t}^{1-\alpha} H_{Y t}^{\alpha}=u^{\alpha} A_{t}^{1+\phi-\alpha} H_{t}^{\alpha-\phi}, \quad H_{Y t} \equiv u_{t} H_{t}, \alpha \in(0,1), \phi \neq \alpha, \phi \neq 0 .
$$

Recall that along the BGP equilibrium $u$ is constant (see Eq. (9)). By plugging (B.1) into (B.2) one obtains:

$$
Y_{t}=u^{-\frac{\alpha}{\phi-\alpha}}\left(\frac{p_{A}}{1-\alpha}\right)^{\frac{1+\phi-\alpha}{\phi-\alpha}} H_{t} .
$$

Since we are interested in computing the effects of changes in the GDP share of cultural capital $(1-\alpha)$ on real per-capita income $\left(Y_{t}\right)$ along the BGP equilibrium, we define $(1-\alpha)$ and $\alpha$ respectively as:

$$
\begin{aligned}
& (1-\alpha) \equiv s \in(0 ; 1) \\
& \alpha \equiv(1-s) \in(0 ; 1) .
\end{aligned}
$$

Thus, (B.3) can also be recast as:

$$
Y_{t}=H_{t} u^{-\frac{1-s}{\phi-1+s}}\left(\frac{p_{A}}{s}\right)^{\frac{\phi+s}{\phi-1+s}} \text {. }
$$

Note that $u$ and $p_{A}$ are both independent of $\alpha$ and, thus, of $s$ in the BGP equilibrium. We are interested in evaluating: $\frac{\partial Y_{t}}{\partial s}$, for a given $H_{t}>0 .{ }^{23}$ After some simple, but lengthy, algebra it is finally possible to obtain:

$$
\frac{\partial Y_{t}}{\partial s}=H_{t}\left(\frac{p_{A}}{s}\right)^{\frac{\phi+s}{\phi-1+s}} \frac{u^{-\frac{1-s}{\phi-1+s}}}{(\phi-1+s)}\left[-\frac{1}{(\phi-1+s)} \ln \left(\frac{p_{A}}{s}\right)-\left(\frac{\phi+s}{s}\right)+\frac{\phi \ln (u)}{(\phi-1+s)}\right] .
$$

23 Since $A$ and $H$ are both state variables in the model, it is well known that we can determine the equilibrium value of their ratio, but not the equilibrium value of each stock in isolation. 
Using the definition of $s$ - Eq. (B.4) - into (B.7), the latter equation can be re-written as:

$$
\frac{\partial Y_{t}}{\partial(1-\alpha)}=H_{t}\left(\frac{p_{A}}{1-\alpha}\right)^{\frac{\phi+1-\alpha}{\phi-\alpha}} \frac{u^{-\frac{\alpha}{\phi-\alpha}}}{(\phi-\alpha)}\left[-\frac{1}{(\phi-\alpha)} \ln \left(\frac{p_{A}}{1-\alpha}\right)-\left(\frac{\phi+1-\alpha}{1-\alpha}\right)+\frac{\phi \ln (u)}{(\phi-\alpha)}\right] .
$$

Clearly, the sign of $\frac{\partial Y_{t}}{\partial(1-\alpha)}$ is non-monotonic and crucially depends on whether $\phi$ is higher or lower than $\alpha$. We now consider in turn each of these two cases.

Case 1: $\phi>\alpha$.

With our parameter values, in particular $p_{A}>1, \alpha \in(0 ; 1)$ and $u \in(0 ; 1)$, and with $H_{t}>0$ and $\phi>\alpha$, the term outside the square brackets in Eq. (B.8) is unambiguously positive, whereas the term inside the square brackets is unambiguously negative. We conclude that in this case $\frac{\partial Y_{t}}{\partial(1-\alpha)}$ is always negative.

Case 2: $\phi<\alpha$.

This restriction implies that $\phi$ can now be either positive or negative. The case $\phi=0$ is explicitly ruled out in our analysis. When $\phi<\alpha$, the term outside the square brackets in Eq. (B.8) is negative, whereas the term inside the square brackets has an ambiguous sign. We conclude that the sign of $\frac{\partial Y_{t}}{\partial(1-\alpha)}$ is also ambiguous. However, we can find a simple sufficient condition for $\frac{\partial Y_{t}}{\partial(1-\alpha)}$ to be positive. According to this condition, what is contained into the square brackets should be definitely negative, implying:

$$
\ln \left(\frac{p_{A}}{1-\alpha}\right)<\frac{(1+\phi-\alpha)(\alpha-\phi)}{(1-\alpha)}+\phi \ln (u) .
$$

Since the LHS of (B.9) is strictly positive, for this condition to be meaningful we also need to impose that the RHS is positive as well:

$$
\frac{(1+\phi-\alpha)(\alpha-\phi)}{(1-\alpha)}+\phi \ln (u)>0 \Rightarrow \frac{\eta-\sqrt{\eta^{2}+4 \varepsilon}}{2}<\phi<\frac{\eta+\sqrt{\eta^{2}+4 \varepsilon}}{2}<\alpha
$$

where:

$$
\begin{aligned}
& \eta \equiv(2 \alpha-1)+(1-\alpha) \ln (u) \\
& \varepsilon \equiv \alpha(1-\alpha)
\end{aligned}
$$

In conclusion, when $\frac{\eta-\sqrt{\eta^{2}+4 \varepsilon}}{2}<\phi<\frac{\eta+\sqrt{\eta^{2}+4 \varepsilon}}{2}<\alpha$, the condition

$$
\ln \left(\frac{p_{A}}{1-\alpha}\right)<\frac{(1+\phi-\alpha)(\alpha-\phi)}{(1-\alpha)}+\phi \ln (u)
$$

is not only algebraically meaningful, but also ensures that an increase in the share of cultural capital in GDP is always associated to an increase of real per-capita income, that is $\frac{\partial Y_{t}}{\partial(1-\alpha)}>0$.

\section{References}

Arnold, L.G., 1998. Growth, welfare, and trade in an integrated model of human-capital accumulation and research. Journal of Macroeconomics 20 (1), 81-105.

Barro, R.J., 1999. Human capital and growth in cross-country regressions. Swedish Economic Policy Review 6 (2), $237-277$.

Bassanini, A., Scarpetta, S., 2002. Does human capital matter for growth in OECD countries? A pooled mean-group approach. Economics Letters 74 (3), 399-405.

Benhabib, J., Spiegel, M.M., 1994. The role of human capital in economic development: evidence from aggregate cross-country data. Journal of Monetary Economics 34 (2), 143-173.

Benhabib, J., Spiegel, M.M., 2005. Human capital and technology diffusion. In: Aghion, P., Durlauf, S.N. (Eds.), Handbook of Economic Growth, vol. 1A. Elsevier-North Holland, Amsterdam, pp. 935-966.

Bucci, A., 2008. Population growth in a model of economic growth with human capital accumulation and horizontal R\&D. Journal of Macroeconomics 30 (3), 1124-1147.

Caselli, F., 2005. Accounting for cross-country income differences. In: Aghion, P., Durlauf, S.N. (Eds.), Handbook of Economic Growth, vol. 1A. Elsevier-North Holland, Amsterdam, pp. 679-741.

Cunningham, S., Banks, J., Potts, J., 2008. Cultural economy: the shape of the field. In: Anheier, H.K., Raj-Isar, Y. (Eds.), The Cultural Economy. Sage Publications, London.

Easterly, W., Levine, R., 1997. Africa's growth tragedy: policies and ethnic divisions. Quarterly Journal of Economics 112 (4), $1203-1250$.

European Commission. 2007. Eurobarometer survey on cultural values within Europe. Directorate-General for Education and Culture. European Commission, Luxembourg.

Eurostat. 2007. Cultural statistics. European Commission Pocketbooks, Luxembourg.

Florida, R., 2002. The Rise of the Creative Class: And How it is Transforming Work, Leisure, Community and Everyday Life. Basic Books, New York.

Florida, R., 2005. The Flight of the Creative Class: The New Global Competition for Talent. Harper Collins, London.

Growiec, J., 2006. Fertility choice and semi-endogenous growth: where Becker meets Jones. B.E. Journal of Macroeconomics: Topics in Macroeconomics 6 (2), Article 10.

Hall, R.E., 1988. Intertemporal substitution in consumption. Journal of Political Economy 96 (2), 339-357.

Islam, N., 1995. Growth empirics: a panel data approach. Quarterly Journal of Economics 110 (4), 1127-1170.

Krueger, A.B., Lindahl, M., 2001. Education for growth: why and for whom? Journal of Economic Literature 39 (4), $1101-1136$. 
Lucas, R.E., 1988. On the mechanism of economic development. Journal of Monetary Economics 22 (1), 3-42.

Marlet, G., van Woerkens, C., 2004. Skills and creativity in a cross-section of Dutch cities. Utrecht School of Economics, Tjalling C. Koopmans Research Institute, Discussion Paper Series, Discussion Paper No. 04-29.

Mathur, V.K., 1999. Human capital-based strategy for regional economic development. Economic Development Quarterly 13 (3), $203-216$.

OECD, 2006. OECD Factbook 2006: Economic, Environmental and Social Statistics. OECD Publications, Paris.

Pritchett, L., 2001. Where has all the education gone? World Bank Economic Review 15 (3), 367-391.

Sacco, P.L., Segre, G., 2009. Creativity, cultural investment and local development: a new theoretical framework for endogenous growth. In: Fratesi, U., Senn, L. (Eds.), Growth and Innovation of Competitive Regions. Springer-Verlag, Berlin.

Santagata, W., 2002. Cultural districts, property rights and sustainable economic growth. International Journal of Urban and Regional Research 26 (1), 9-23.

Scott, A.J., 2000. The Cultural Economy of Cities. Sage Publications, London.

Strulik, H., 2005. The role of human capital and population growth in R\&D-based models of economic growth. Review of International Economics 13 (1), $129-145$.

Temple, J., 1999. A positive effect of human capital on growth. Economics Letters 65 (1), 131-134.

Temple, J., 2001. Generalizations that aren't? Evidence on education and growth. European Economic Review 45 (4-6), 905-918.

Throsby, D., 2001. Economics and Culture. Cambridge University Press, Cambridge.

Throsby, D., 2008. The concentric circles model of the cultural industries. Cultural Trends 17 (3), 147-164.

Topel, R., 1999. Labor markets and economic growth. In: Ashenfelter, O., Card, D. (Eds.), Handbook of Labor Economics. Elsevier-North Holland, Amsterdam, pp. 2943-2984.

Uzawa, H., 1965. Optimum technical change in an aggregative model of economic growth. International Economic Review 6, $18-31$.

Wößmann, L., 2003. Specifying human capital. Journal of Economic Surveys 17 (3), 239-270. 